Marcin M. Chojnacki

Dominika Staszenko

University of Lodz

\title{
What Will Be the Future of the Past? Report from ARCHIVES OF/FOR THE FUTURE The NECS 2015 Conference
}

Introduction

European Network for Cinema and Media Studies (NECS) Conference is one of the biggest and the most prestigious academic events dedicated to the audiovisual culture in Europe. Each year, it takes place in a different country. The 2015 edition was held on June 17-20 in Poland. The event was organized by representatives of the University of Lodz in cooperation with the SWPS University. The major part of conference took place in the new building of the Faculty of Philology in the city of Lodz which lent the space for papers of nearly 350 researchers from thirty three countries, who overall delivered approximately 160 presentations each day. Apart from listening to highly inspiring presentations, the NECS 2015 Conference attendees had a chance to take part in Graduate Workshop and Transmediality Workshop (held on the premises of Art_Inkubator - a cultural institution located on the Tymienieckiego Street), enjoy screenings, take part in Project Forum, engage in meetings of work groups, participate in Publishers Forum and experience four keynote lectures delivered by well-known artists and researchers. In our report we would like to focus on the latter aspect of the Conference as well as one panels dedicated to Video Game Studies. 
Keynotes

Krzysztof Wodiczko: Critical Archive

The first keynote lecture titled Critical Archive was delivered by Krzysztof Wodiczko, an artist and art theorist well known for arranging public projections in order to present statements of immigrants, the homeless or victims of domestic violence. During his speech Wodiczko recalled examples of projects that focused on language, speech, contact with strangers, and xenophobia. In all described works (Alien Staff, Mouthpiece, Dis-Armor and Tijuana Projection) the focus was placed on the medium and how it affects the utterance. The presented pieces posed the question of how the situation in which the speaker makes his or her pronouncement (how, when, where does it take place?) elicits in listeners strong emotional reaction. All these conditions build a new context, something unique and appealing, especially for those who watch this type of performance. We found it very interesting that technology, such as wearable speakers and monitors or public projections, allows the participants of Wodiczko's projects to confess, express their feelings or to make contact with recently encountered people.

During the discussion with professor Ryszard W. Kluszczyński (Chair of School of Media and Audiovisual Culture, University of Lodz) the question of using people's speech, life experience, and emotions as an art material and associated with this difficulties arose. To answer it, Krzysztof Wodiczko stated that he treats this kind of art as a therapy for the speakers as well as for the listeners, because these both groups achieve a similar impression as a result of participation in the project. In most cases their contribution is a beginning of dealing with the serious problem, and the occasion to share feelings and reflections publicly, which can serve therapeutic purpose. Once again medium became the most important factor - it encourages to talk with the others about delicate matters. It was really surprising at first, but as artist marked during describing the outcomes of one of his projects, "it's sometimes easier to tell the truth in public space than to each other in the domestic, intimate environment".

Giovanna Fossati: Bridging theory and practice of film heritage. On preservation, restoration, presentation and access

The role of media was also discussed by another keynote speaker - Giovanna Fossati, the Chief Curator at the EYE Film Institute Netherlands and Professor of Film Heritage and Digital Film Culture at the University of Amsterdam. Her lecture was focused on new types of archives, the problem of film digitalization and differences 
between various frameworks of archival practices. Professor Fossati referred to her reflections about difficulties affecting preservating film heritage described earlier in the book From Grain to Pixel. The Archival Life of Film in Transition and proposals of other researchers. She enumerated couple of theoretical frameworks fixing certain approaches to understanding film, such as original artifact, state of art, dispositif or performance, and put stress on the aspect of researchers' awareness of available tools and used film techniques in the process of archiving. Large part of them seemed to be useful as a part of Digital Media Studies including problem of video games preservation.

Professor Fossati identified also three conceptual framings: document, monument, event, and recognized them appropriable for archiving practice. Later in the discussion with Łukasz Biskupski (Institute for Cultural Studies, SWPS University) both researchers talked about fast-changing situation of digitalization and considering the archiving field a specific tradition represented by particular institutions. There also appeared an interesting concept of treating restoration as a simulation, and Giovanna Fossati pointed out that nowadays, digital tools are more flexible and effective than photochemical tools, therefore they function in a way that recalls simulating other medium. In a summary, thoughts about data storage and suggestion to treat it as a general problem needed to be taken very seriously as well as to make archives more accessible for the public occurred.

\section{Oliver Grau: The Complex Expression of Digital Art}

The third keynote lecture was delivered by Oliver Grau, Chair Professor for Image Science at the Center of Image Science at the Danube University. In his speech $\mathrm{Mr}$ Grau described digital art as more complicated and having greater potential than more traditional forms and therefore requiring a more comprehensive reflection. In his opinion, new media art touches upon serious current issues, questions important for todays' society and researchers. However, it is not always sufficiently represented in museums or galleries and rather frequently ignored by the establishment. This is precisely why digital art is still most frequently exhibited at festivals, as Grau suggested, because traditional institutions do not have adequate knowledge and do not see value of presenting such artworks. Even though that new media artists correspond with fears of modern society like data-terrorism, identity theft or privacy spying and very consciously point out present global dangers they operate outside the mainstream. Digital art reflection, due to its complexity, should consist of interdisciplinary studies and tools, especially in the field of archivisation. Oliver Grau remarked that 
new media art is still not restored and archived properly owing to the fact that it is difficult to decide who is responsible for preservation of digital artworks. During the following discussion opened by Antonio Somaini (Professor of Film, Media, and Visual Culture Theory at the Université Sorbonne Nouvelle - Paris 3), Marysia Lewandowska, a keynote speaker of the forthcoming day, suggested that maybe we need new institutions, something different than museums or archives, which will focus on appropriate methods and solutions.

\section{Marysia Lewandowska: Museum Commons. Research driven art practice and the public function of archives, collections and exhibitions}

The last keynote lecture, closing the whole conference, was delivered by previously mentioned Marysia Lewandowska - Visiting Professor at the CUHK Faculty of Arts and Artist in Residence at the Asia Art Archive in Hong Kong through 2014 and 2015. She started her speech with a presentation of prematurely deceased Ewa Mikina, who was a well-known historian, media art critic, theorist, curator of exhibitions, and also the originator of the idea of cyberculture. During this remembrance Lewandowska also harked back to the Media and Ethics conference, which was held in Helsinki in 1996. She recalled that back then researchers (led by Oliver Grau) consulted the role of museums, galleries and other media institutions in light of the emerging media such as Internet, CD-ROMs and telemetrics. They talked about how institutions should react to changes caused by various media and discussed them as a critical and dialogical spaces. Moreover, as Lewandowska said, it is very strange that today we are facing the same problems and asking the same questions as back then.

According to Lewandowska, archives are like collections, because both of them are connected to property, multiple authors and previous owners. But what sets them apart is that archives designate a territory, not a particular narrative as collections do. Because of this, archives are a discursive terrain and have creative potential. Furthermore, Lewandowska mentioned that "in archives, interpretations are invited - not already determined which creates a space for archive authors". She admitted that issues related to ownership are her central concern of contemporary archive and this is the way she works with it. Then the keynote speaker told a few words about her projects called Enthusiasts and Tender Museum to proceed to wider reflection about public function of an archive, role of amateur documentalists, women public rights and differences between public and private sphere. 


\section{Game Studies Panel}

The topics of the keynote lectures were closely connected with papers presented by the conference participants. Most of them focused on problems of new media archivisation, film heritage, digitalization, amateur materials, canon, archival research methods, nostalgia, and memories. One of the panels was also dedicated to Video Game Studies and chaired by Maria B. Garda (University of Lodz) - researcher interested in the issue of archiving and preserving digital games, among others. This panel contained three papers.

\section{Biljana Mitrovic: The New Media Recording and Archiving - By/In the New Media: The Video Game Playing Experience}

Biljana Mitrovic from the University of Art in Belgrade was talking mostly about Massive Multiplayer Online Role Playing Games, in which problem with archiving is especially apparent. Mrs Mitrovic began her speech with an ascertainment that the number of players in World of Warcraft is the same as the entire Swedish population. She also mentioned that this is not an exception, because the most popular online games have a huge number of players, for example Guild Wars 2 - 460,000 users.

The researcher pointed out that already in 2002 there was a conviction that there is no such thing as archived games. Therefore, the question about the sustainability of online gaming and the quality of studying it if we are not able to keep maps, servers and other signs of gameplay arises. Mrs Mitrovic also suggested making a distinction between games' archive and an archive of the experience of playing. This is why she presented three ways to counteract the transience of online gaming in the spirit of archiving the gameplay experience. The first way was referred to as creating personal archives of photos, screens, videos and any other documents connected with specific moments in games. Mrs Mitrovic noticed that people are already doing it and moreover, they share self-captured materials using social platforms such as YouTube. This creates something that can be recognized as a public archive of game recordings.

The second described process relates to a slightly different perspective, because Mrs Mitrovic spoke about the phenomenon of creating life description of video games heroes, the so-called "epic biographies". This practice is interesting mainly due to the interaction of the players expressed by discussions in the comments. The third, last-mentioned way of archiving the experience with digital medium was online streaming. Researcher from Belgrad argued its importance because such practice blurs the boundaries between the medium carrying the message, and medium as information storage. At the end of her lecture Mitrovic subjected to discuss issues 
related to game developers and their role as archivists. However, the overtone of the lecture was connected with understanding archive of digital media not as institution, but as a personal, symbiotic system.

Paweł Frelik: "Where Is That Beam, Scotty?": Towards a Science Fiction Video Game Archive

The second presentation in the panel was Paweł Frelik's (Maria Curie-Sklodowska University) “Where Is That Beam, Scotty?": Towards a Science Fiction Video Game Archive. The researcher stated that the problem with games is that people rarely collect them. He focused on the case of Library of Congress which brings together only three thousands of game copies, 1.5 thousand strategy guides and fifty examples of gameplay footage on VHS and DVD. Mr Frelik outlined some current archiving efforts made in the United States such as Stephen M. Cabrinety's Collection in the History of Microcomputing and initiatives taken by the University of Michigan, the University of Illinois and the University of Texas. The Polish researcher pointed out that the biggest obstacle for institutions is a cataloguing system. Video games from 1980s and 1990s are threatened by becoming lost because of the currently unused retro consoles and computers. Mr Frelik mentioned that people are trying to collect game magazines or screens, but he paid attention to the fact that this material signs are not relevant to the experience of gameplay. He also said that people currently archive material objects such as physical medium or collector's editions of games, but what about digital materials? How can we archive digital games, mods, unofficial levels, concept arts, game code and gameplay? In the conclusion, Mr Frelik talked about issues related to blogs, forums, databases and other things connected with games, but non-existent in material form, and problems with archiving them.

\subsection{Mateusz Felczak: Gather, Manage, Play - The Case of the Steam Platform and Its Influence on the PC Video Games}

The third paper was delivered by Mateusz Felczak from the Jagiellonian University. His speech focused on Steam game library. He talked about Steam Platform as a database which contains various information about games and their users, for example statistics according to which $37 \%$ of games bought on Steam have never been installed and run. However, not all available figures should be considered as authentic, for instance, release dates are not always genuine because in some cases they are not related to game premiere but with its appearance on Steam. This is why many retro titles, such as Doom II [id Software, 1994], have misinforming release dates. Another problematic 
issue is a tag system used by platform users predominantly based on individual opinions and experiences that not always correspond with the actual game content. Later, Mr Felczak mentioned the new Discovery Queue feature that allows gamers to find interesting titles similar to already owned ones and its impact on searching the Steam library, and explained the controversies connected with paid game modifications or impossibility of erasing digital games from Steam account of that time.

\subsection{Discussion}

In the following discussion, the speakers and the audience focused on essential problems of video game archivisation. One of the main topics were the difficulties in indicating who is responsible for collecting and preserving material medium like floppy disks or cartridges as well as their digital counterparts. This issue inscribes pretty well in a much wider field of new media reflection signalized earlier and drawn out by many conference participants. The question of whether creators, publishers, researchers or maybe amateur collectors are accountable for saving video game heritage is still open and hard to answer unambiguously. Maybe in near future cultural institutions will find a solution to avoid obstacles of this type, but nowadays traditional museums or archives seem insufficient. It is a great challenge to be faced not only by researchers or media historians but, in our opinion, by all people interested in preserving artifacts of modern popular culture.

\section{Conclusion}

The NECS 2015 Conference was not only an extraordinary occasion to meet with and listen to the experts from many parts of the world, but also a chance to extend research perspectives adaptable also for Game Studies. We learned that all digital media researchers share many adversities arising from the very nature of the object of their interest and that there is a prospect of interdisciplinary cooperation in order to improve the process of creating archives and making them more accessible for the public. We hope that the main subject of the latest NECS conference will continually be in the centre of attention in the near future because - as artists and scientific authorities present at the event have pointed out - there is still a lot to do in this matter. 